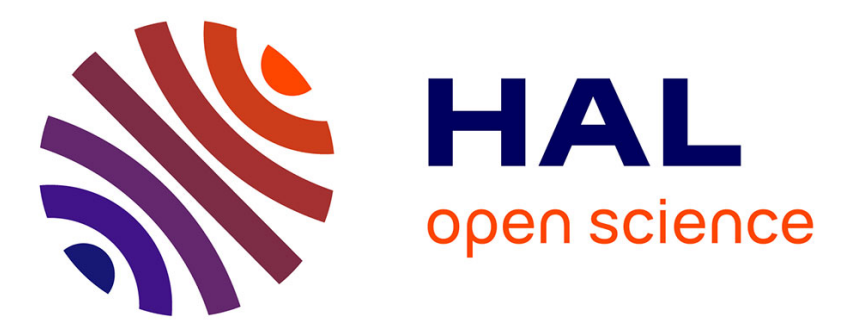

\title{
Photo-physical properties of donor-acceptor-radical triad based on functionalized tetrathiafulvalene and nitronyl nitroxide radical
}

Haiet Douib, Marin Puget, Yan Suffren, Fabrice Pointillart, Kevin Bernot, Boris Le Guennic, Olivier Cador, Abdelkrim Gouasmia, Lahcène Ouahab

\section{To cite this version:}

Haiet Douib, Marin Puget, Yan Suffren, Fabrice Pointillart, Kevin Bernot, et al.. Photo-physical properties of donor-acceptor-radical triad based on functionalized tetrathiafulvalene and nitronyl nitroxide radical. Dyes and Pigments, 2017, 145, pp.285-293. 10.1016/j.dyepig.2017.06.010 . hal-01578543

HAL Id: hal-01578543

https://hal-univ-rennes1.archives-ouvertes.fr/hal-01578543

Submitted on 11 Sep 2017

HAL is a multi-disciplinary open access archive for the deposit and dissemination of scientific research documents, whether they are published or not. The documents may come from teaching and research institutions in France or abroad, or from public or private research centers.
L'archive ouverte pluridisciplinaire HAL, est destinée au dépôt et à la diffusion de documents scientifiques de niveau recherche, publiés ou non, émanant des établissements d'enseignement et de recherche français ou étrangers, des laboratoires publics ou privés. 


\section{Photo-physical Properties of Donor-Acceptor-Radical Triad Based on Functionalized Tetrathiafulvalene and Nitronyl Nitroxide Radical}

Haiet Douib, ${ }^{\mathrm{a}, \mathrm{c}}$ Marin Puget, ${ }^{\mathrm{b}}$ Yan Suffren, ${ }^{\mathrm{b}}$ Fabrice Pointillart, ${ }^{\mathrm{a}}$ Kevin Bernot, ${ }^{\mathrm{b}}{ }^{\mathrm{b}}$ Boris Le Guennic, ${ }^{\mathrm{a}}$ Olivier Cador, ${ }^{\mathrm{a}}$ Abdelkrim Gouasmia, ${ }^{\mathrm{c}}$ Lahcène Ouahab ${ }^{\mathrm{a}}$

${ }^{a}$ Institut des Sciences Chimiques de Rennes, UMR 6226 CNRS-Université de Rennes 1, 263 Avenue du Général Leclerc, 35042 Rennes Cedex, France

${ }^{b}$ Institut des Sciences Chimiques de Rennes, UMR CNRS 6226, INSA Rennes, 20 Avenue des buttes de Coesmes, 35708 Rennes, France.

c Laboratoire des Matériaux Organiques et Hétérochimie (LMOH), Département des sciences de la matière, Université Larbi Tébessi de Tébessa, Route de Constantine 12002, Tébessa, Algérie.

Corresponding authors: fabrice.pointillart@univ-rennes1.fr; $\underline{\text { kevin.bernot@insa-rennes.fr }}$

\section{Highlights}

- An Acceptor-Donor-Radical triad with tetrathiafulvalene donor and nitronyl nitroxide radical was synthesized.

- Tetrathiafulvalene radical cation oxidized form is reachable without alteration of the nitronyl nitroxide radical.

- Both tetrathiafulvalene-based molecular skeleton and nitronyl nitroxide phosphorescence can be observed.

- The ratio of the emission intensities can be tuned depending on the irradiation energy.

\section{Abstract}

An acceptor-donor-radical triad based on tetrathiafulvalene (TTF)-fused (benzimidazol-2-yl)-pyridine (bzip) which is alkylated with a nitronyl nitroxide (NIT) radical derivative, has been designed and synthetized. Its X-ray structure has been refined showing a complex arrangement of head-to-tail dimers of the TTF-bzip moieties and a 1D network of 
short contacts between the NIT radicals. Its electrochemical behavior has been studied by cyclic voltammetry (CV) showing that the TTF and NIT moieties can be reversibly and independently oxidized. The occurrence of intramolecular ligand charge transfers (ILCT) of both TTF $\rightarrow$ bzip and TTF $\rightarrow$ NIT nature has been evidenced by UV-visible electronic absorption spectroscopy coupled to TD-DFT calculations. Moreover, these calculations and RPE measurements confirmed the radical form $(S=1 / 2)$ of the compound as well as the spin density mainly localized on the methyl-benzo-[1-oxyl-3-oxide-4,4,5,5-tetramethylimidazolin2-yl] unit. Both emissions of the NIT radical and TTF-based molecular skeleton have been observed with a tunable intensity ratio depending on the irradiation energy. Finally, this new triad may be a valuable candidate for the construction of multi-property compounds by coordination of metallic ions either on the TTF-based molecular skeleton or on the NIT moieties.

Keywords: Tetrathiafulvalene, nitronyl nitroxide radical, triads, electrochemistry, photophysical properties

\section{Graphical abstract:}

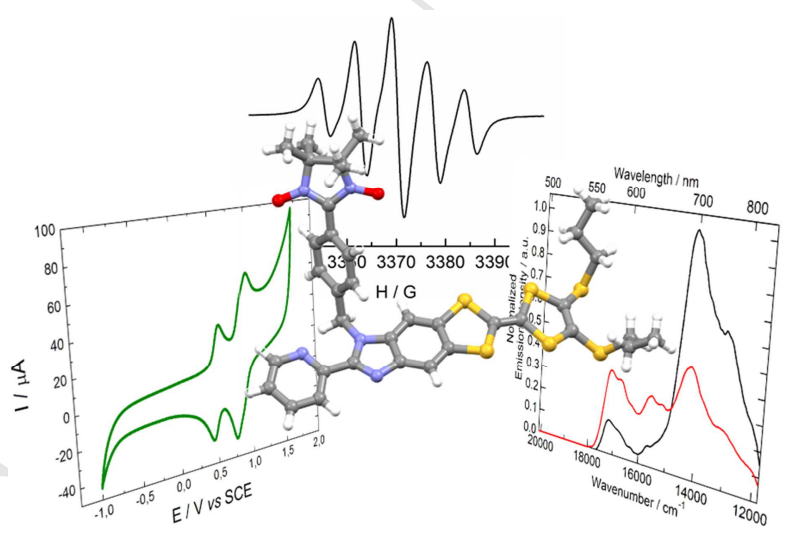

\section{Introduction}

Chemists and physicists have been working hand-in-hand for more than two decades in order to design multifunctional materials with controllable physicochemical properties. In particular, they have tried to conceive molecular architectures able to force interactions between these properties until reaching a synergetic effect between them. Multiferroism and magneto-chiral dichroism are maybe the most representative examples of synergy between 
several different physical properties[1]-[3]. In this line, this work is focused on the search of molecular compounds that exhibit both electronic conductivity and magnetic behavior. To obtain such compounds, we used the extremely rich chemistry based on the tetrathiafulvalene (TTF) core in order to take advantage of its redox activity and potential electronic conductivity[4]. It has been demonstrated that a fruitful strategy is to add to the TTF core localized electrons thanks to transition metals $(3 d$ and $4 d)$ [5]-[10] or lanthanides[11]-[12]. Such $\pi-d$ and $\pi-f$ systems have shown exciting transport properties such as antiferromagneticsuperconductor or magnetic-field induced superconducting transition[13]-[14] but also have given rise to redox-active [15]-[18], or luminescent single-molecule magnets (SMM)[19][20]. The successes in obtaining such multi-property molecular systems were guaranteed thanks to two approaches that allow the observation of interactions between mobile electrons of the organic network and localized electrons of the paramagnetic metals: i) through-space interactions or ii) covalent bonds. Whereas the first strategy leads to very weak $\pi-d / \pi-f$ interactions, the second one might enhance them. The "through-space" approach is commonly used thanks to a plethora of functionalization of the TTF core with organic moieties suitable to coordinate metal ions (amino, nitrile, phenolate, phosphino, $\beta$-diketonate, pyrazine, pyrimidine, pyridine, pyridine-N-oxide, bipyridine...)[5],[21],[22]. All of these organic coordinating groups are magnetically innocent $(S=0)$. However, an underdeveloped strategy consists in the functionalization of the TTF core with a stable organic radical $(S=1 / 2)$ to play the magnetic relay between the $\pi$ mobile electrons and the paramagnetic metal. The design and elaboration of such "TTF-radical" dyads are very challenging and to date only few researchers took this synthetic route: Sugawata et al.[23]-[26] developed the functionalization of the TTF core with nitrosyl or nitronyl nitroxide spin carriers while Yamaguchi et al.[27] and Datta et al.[28],[29] studied such donor-radical dyads from a computational point of view. Additionally, Pilkington et al.[30],[31] used the verdazyl moiety as stable radical while Veciana et al. exploited the perchlorotriphenylmethyl radicals[32]-[36] to design their dyads.

In our group, a family of donor-acceptor dyads based on the 2-(4,5-(4,5bis(propylthio)-tetrathiafulvalenyl)-1H-benzimidazol-2-yl)-pyridine molecular skeleton 1[37],[38] has been previously designed and alkylated with various organic moieties such as 2-pyridyl[39], dimethyl-2,2'-bipyridyl,[40] di-(pyrazol-1-yl)-4-pyridyl[40] and 4-pyridyl- $N$ oxide[41]. In the present work, following this synthetic strategy, 1 has been alkylated with the 4-bromomethylbenzo(1-oxyl-3-oxide-4,4,5,5-tetramethylimidazolin-2-yl) organic radical 2 and leads to the formation of the 2-\{1-[methylbenzo(1-oxyl-3-oxide-4,4,5,5- 
tetramethylimidazoline)]-4,5-[4,5-bis(propylthio)-tetrathiafulvalenyl]-1 $H$-benzimidazol-2yl \}pyridine acceptor-donor-radical triad $\mathbf{3}$. In the next lines, X-ray structures of $\mathbf{2}$ and $\mathbf{3}$ are analyzed as well as the electrochemical, photo-physical and magnetic properties of $\mathbf{3}$.

\section{Experimental Section}

\subsection{General}

The ligand 2-(4,5-(4,5-bis(propylthio)-tetrathiafulvalenyl)-1H-benzimidazol-2-yl)pyridine[38] 1 and the organic radical precursor 4-bromo-methylbenzo(1-oxyl-3-oxide4,4,5,5-tetramethylimidazolin-2-yl) 2[42]-[44] were synthesized following previously reported methods. The 4-(bromomethyl)benzaldehyde was purchased from Acros company while all other reagents were purchased from Aldrich Co., Ltd. and used without further purification.

\subsection{Synthesis}

4-bromomethylbenzo(1-oxyl-3-oxide-4,4,5,5-tetramethylimidazolin-2-yl) (2). Slow evaporation of a $\mathrm{CH}_{2} \mathrm{Cl}_{2} / n$-hexane mixture affords single-crystal suitable for X-ray diffraction studies.

\section{2-\{1-[methylbenzo(1-oxyl-3-oxide-4,4,5,5-tetramethylimidazoline)]-4,5-[4,5-}

\section{bis(propylthio)-tetrathiafulvalenyl]-1 $H$-benzimidazol-2-yl $\}$ pyridine $\quad(3)$. 2-(4,5-(4,5-}

bis(propylthio)-tetrathiafulvalenyl)-1H-benzimidazol-2-yl)-pyridine 1 (33.3 mg, $0.06 \mathrm{mmol}$ ) and $\mathrm{K}_{2} \mathrm{CO}_{3}$ (13.3 mg, $0.10 \mathrm{mmol}, 1.5$ equiv) were added to anhydrous DMF ( $3 \mathrm{~mL}$ ), and then the mixture was stirred for $30 \mathrm{~min}$ under argon. A solution of anhydrous DMF $(2 \mathrm{~mL})$ containing 4-bromo-methyl-benzo-(1-oxyl-3-oxide-4,4,5,5-tetramethylimidazolin-2-yl) 2 (15 $\mathrm{mg}, 0.046 \mathrm{mmol}, 0.8$ equiv) was added, and the resulting mixture was stirred for $2 \mathrm{~h}$ at room temperature. Then additional $\mathrm{K}_{2} \mathrm{CO}_{3}(13.3 \mathrm{mg}, 0.10 \mathrm{mmol}, 1.5$ equiv) and of 4-bromomethyl-benzo-(1-oxyl-3-oxide-4,4,5,5-tetramethylimidazolin-2-yl) (1) (10 mg, $0.03 \mathrm{mmol}$, 0.5 equiv) were added. The mixture was stirred at room temperature overnight under argon atmosphere.

The solvents were eliminated under vacuum and the residue was dissolved in $\mathrm{CH}_{2} \mathrm{Cl}_{2}$, filtered, concentrated to $5 \mathrm{~mL}$ and finally $\mathrm{n}$-hexane $(5 \mathrm{~mL})$ was added. Slow evaporation in the dark gave green single crystals of 3 suitable for X-ray study. Yield: $37 \mathrm{mg}$ (75\%). Anal. 
Calcd (\%) for $\mathrm{C}_{36} \mathrm{H}_{38} \mathrm{~N}_{5} \mathrm{O}_{2} \mathrm{~S}_{6}$ : C 56.47, H 4.97, N 9.15; found: C 56.55, H 5.01, N 9.09. I.R. (KBr): 2959, 2926, 2866, 2853, 1632, 1586, 1565, 1443, 1423, 1387, 1364, 1320, 1220, $1162,1103,851,786,738,701,613$ and $540 \mathrm{~cm}^{-1}$.

\subsection{Crystallography}

Single crystals of $\mathbf{2}$ and $\mathbf{3}$ were mounted on a D8 VENTURE Bruker-AXS diffractometer for data collection $\left(\mathrm{MoK}_{\alpha}\right.$ radiation source, $\lambda=0.71073 \AA$ ), from the Centre de Diffractométrie (CDIFX), Université de Rennes 1, France. Structures were solved with a direct method using the SHELXT program[45] and refined with a full matrix least-squares method on $\mathrm{F}^{2}$ using the SHELXL-14/7 program[46]. Crystallographic data are summarized in Table 1. Complete crystal structure results as a CIF file including bond lengths, angles, and atomic coordinates are deposited as Supporting Information.

\subsection{Physical Measurements.}

The elementary analyses of the compounds were performed at the Centre Régional de Mesures Physiques de l'Ouest, Rennes. Cyclic voltammetry was carried out in $\mathrm{CH}_{2} \mathrm{Cl}_{2}$ solution, containing $0.1 \mathrm{M}$ of $\mathrm{N}\left(\mathrm{C}_{4} \mathrm{H}_{9}\right)_{4} \mathrm{PF}_{6}$ as supporting electrolyte. Voltamograms were recorded at $100 \mathrm{mV} . \mathrm{s}^{-1}$ at a platinum disk electrode. The potentials were measured versus a saturated calomel electrode (SCE). Absorption spectra were recorded on a Varian Cary 5000 UV-Visible-NIR spectrometer equipped with an integration sphere. The solid and solution emission and excitation spectra were measured using a Horiba-Jobin Yvon Fluorolog-3® spectrofluorimeter, equipped with a three slit double grating excitation and emission monochromator with dispersions of $2.1 \mathrm{~nm} / \mathrm{mm}$ (1200 grooves $/ \mathrm{mm})$. The steady-state luminescence was excited by unpolarized light from a $450 \mathrm{~W}$ xenon $\mathrm{CW}$ lamp and detected at a $90^{\circ}$ angle for diluted solution and for solid state measurements by a red-sensitive Hamamatsu R928 photomultiplier tube (sensitivity 190-860 nm). Spectra were reference corrected for both the excitation source light intensity variation (lamp and grating) and the emission spectral response (detector and grating). Appropriate filters were used to remove the residual excitation laser light, the Rayleigh scattered light and associated harmonics from spectra. The emission/excitation spectra recordings were realized on powder sample mounted directly onto copper plates using conductive silver glue and cooled in an optical cryostat capable of reaching temperature down to $77 \mathrm{~K}$ through a continuous nitrogen liquid flow and 
a nitrogen atmosphere inside the sample chamber (OptistatCF, Oxford Inst.). The luminescence of solution has been measured at $77 \mathrm{~K}$, the sample is introduced in a quartz capillary tube, which it is placed inside a small Dewar containing nitrogen liquid. The dc magnetic susceptibility measurements were performed on solid polycrystalline sample with a Quantum Design MPMS-XL SQUID magnetometer between 2 and $300 \mathrm{~K}$ in applied magnetic field of $0.2 \mathrm{~T}$ for temperatures of $2-20 \mathrm{~K}$ and $1 \mathrm{~T}$ for temperatures of $20-300 \mathrm{~K}$. These measurements were all corrected for the diamagnetic contribution as calculated with Pascal's constants. EPR spectrum was recorded to room temperature in toluene solution with a BRUKER EMX X-band ESR spectrometer equipped with an OXFORD cryostat.

\subsection{Computational Details}

DFT geometry optimizations and TD-DFT excitation energy calculations of $\mathbf{3}$ were carried out with the Gaussian 09 (revision D.01) package[47] employing the PBE0 hybrid functional[48],[49]. All the atoms were described with the SVP basis sets[50]. The first 100 mono-electronic excitations were calculated. In all steps, a modelling of bulk solvent effects (solvent $=$ dichloromethane) was included through the Polarizable Continuum Model (PCM)[51], using a linear-response non-equilibrium approach for the TD-DFT step[52],[53]. Molecular orbitals were sketched using the Gabedit graphical interface[54]. Spin density distribution was drawn using VESTA code (version 3.3.1)[55].

\section{Results and Discussion}

\subsection{Synthesis}

The elaboration of ligands involving both TTF and nitronyl nitroxide remains challenging and only few examples have been previously published[23]-[26]. The synthetic pathway toward the donor-acceptor 2-\{1-[methylbenzo(1-oxyl-3-oxide-4,4,5,5tetramethylimidazoline)]-4,5-[4,5-bis(propylthio)-tetrathiafulvalenyl]-1 $H$-benzimidazol-2-

yl \}pyridine $\mathbf{3}$ is outlined in scheme 1. Its design required the synthesis of a nitronyl nitroxide radical with a benzo-bromo-methyl moiety as substituent. To obtain it, the classical synthetic route is employed i.e. a direct condensation of the 2,3-bis(hydroxyamino)-2,3-dimethylbutane base in presence of the 4-(bromomethyl)benzaldehyde that leads to the formation of the reduced form of $\mathbf{2}$. The desired nitronyl nitroxyde $\mathbf{2}$ is obtained by oxidation of the latter compound with sodium periodate. Finally, the 2-(4,5-(4,5-bis(propylthio)- 
tetrathiafulvalenyl)-1H-benzimidazol-2-yl)-pyridine ligand $\mathbf{1}$ was alkylated with the bromo nitronyl nitroxide derivative at room temperature to give 3 . It is worth to notice that the alkylation step must be performed at room temperature to prevent the degradation of 2 .
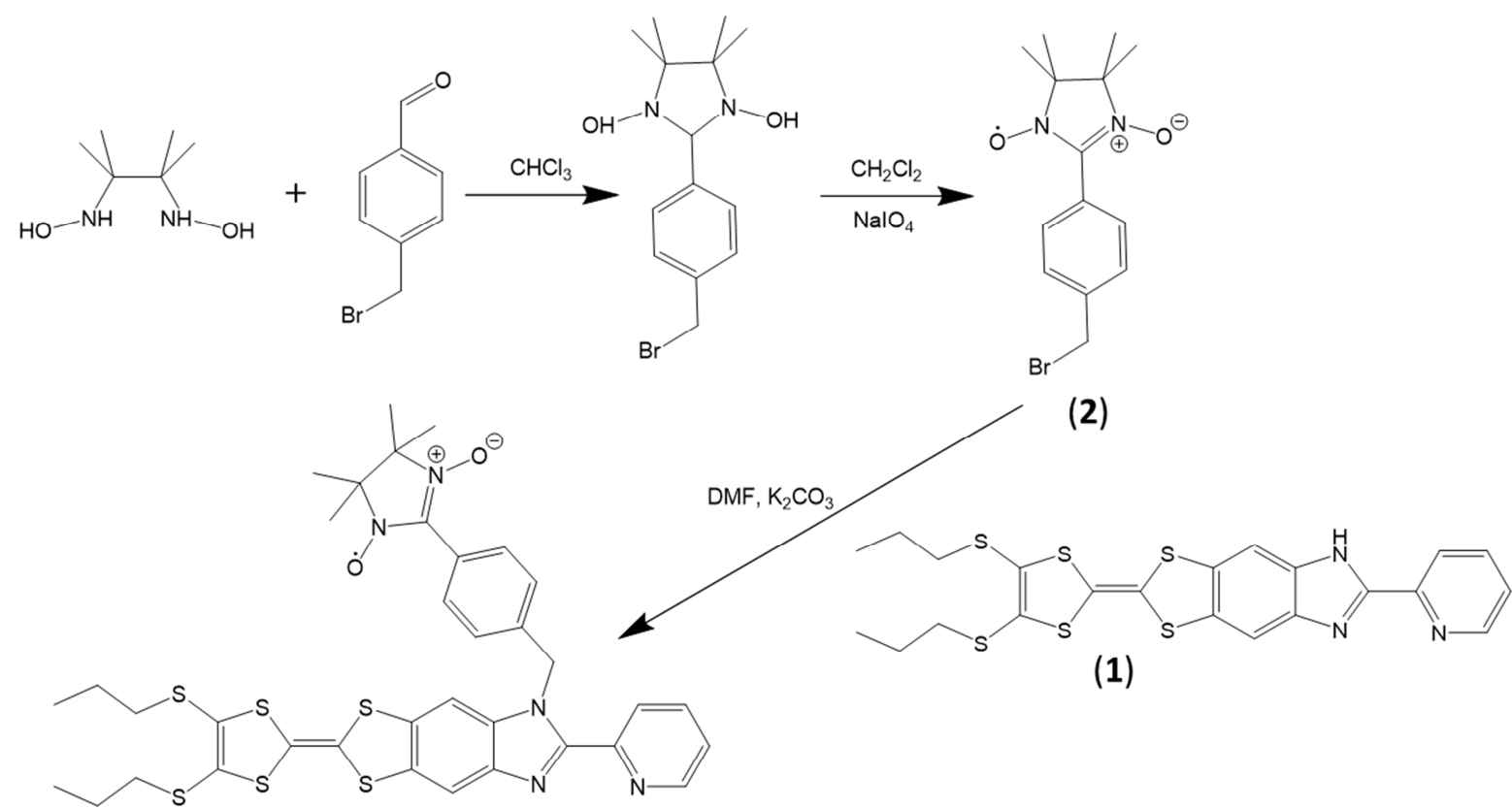

(3)

Scheme 1. Synthetic route for compounds 2 and 3.

\section{$3.2 \mathrm{X}$-ray structures}

Compound 2 crystallizes in the $C 2 / c\left(\mathrm{~N}^{\circ} 15\right)$ monoclinic space group (Table 1). The asymmetric unit is composed of one molecule of 2 (Fig. S1).. The crystal packing does not reveal any $\pi-\pi$ interaction between the phenyl rings. The main interactions between the molecules take place between the $\mathrm{N}-\mathrm{O}$ groups $(\mathrm{O} 2 \cdots \mathrm{O} 2=4.039 \AA$ and $\mathrm{O} 1 \cdots \mathrm{O} 1=4.403 \AA)$ and between the bromine atom and the phenyl ring (Fig. S2).

Table 1. X-ray crystallographic data for $\mathbf{2}$ and $\mathbf{3}$.

\begin{tabular}{ccc}
\hline Compounds & $\mathbf{2}$ & $\mathbf{3}$ \\
& $\mathrm{CCDC} 1535280$ & $\mathrm{CCDC} 1535281$ \\
\hline Formula & $\mathrm{C}_{14} \mathrm{H}_{18} \mathrm{BrN}_{2} \mathrm{O}_{2}$ & $\mathrm{C}_{72} \mathrm{H}_{76} \mathrm{~N}_{10} \mathrm{O}_{4} \mathrm{~S}_{12}$ \\
$\mathrm{M} /$ g.mol & \\
\hline Crystal system & 326.2 & 1530.14 \\
\hline Space group & Monoclinic & Triclinic \\
\hline & $C 2 / c\left(\mathrm{~N}^{\circ} 15\right)$ & $P-1\left(\mathrm{~N}^{\circ} 2\right)$ \\
\hline Cell parameters & $a=23.8847(12) \AA$ & $a=13.6015(14) \AA$ \\
& $b=10.6482(6) \AA$ & $b=16.2250(20) \AA$ \\
& $c=11.7735(6) \AA$ & $c=17.6720(20) \AA$ \\
& $\beta=95.459(2){ }^{\circ}$ & $\alpha=68.538(4){ }^{\circ}$ \\
\end{tabular}




\begin{tabular}{ccc} 
& & $\gamma=88.706(4){ }^{\circ}$ \\
\hline Volume $/ \AA^{3}$ & $2980.8(3)$ & $3609.6(7)$ \\
\hline$Z$ & 8 & 2 \\
\hline $\mathrm{T} / \mathrm{K}$ & $150(2)$ & $150(2)$ \\
\hline $2 \theta$ range $/{ }^{\circ}$ & $5.34 \leq 2 \theta \leq 55.04$ & $5.76 \leq 2 \theta \leq 55.96$ \\
\hline$\rho_{\text {calc }} /{\mathrm{g} . \mathrm{cm}^{-3}}^{-1}$ & 1.454 & 0.420 \\
\hline$\mu / \mathrm{mm}^{-1}$ & 2.758 & 77927 \\
\hline Number of reflections & 3411 & 16508 \\
\hline $\begin{array}{c}\text { Independent } \\
\text { reflections }\end{array}$ & 2655 & 0.0757 \\
\hline$R_{\text {int }}$ & & 10449 \\
\hline$F o^{2}>2 \sigma(F o)^{2}$ & 0.0523 & 883 \\
\hline Number of variables & 1336 & $0.0729,0.1796$ \\
\hline$R_{1}, w R_{2}$ & 172 &
\end{tabular}

Compound 3 crystallizes in the $P-1\left(\mathrm{~N}^{\circ} 1\right)$ triclinic space group (Table 1). The asymmetric unit is composed of two molecules of $\mathbf{3}$ (Fig. 1). The X-ray structure of 3 highlights the success of the alkylation reaction since the two N3 and N8 nitrogen atoms are alkylated with the methylbenzo(1-oxyl-3-oxide-4,4,5,5-tetramethylimidazoline) radical moiety. Several structural differences distinguish the two crystallographically independent molecules. The molecule with the sulfur atoms S1 to S6 is defined as molecule A while the molecule with sulfur atoms S7 to S12 is defined as molecule B. i) The angles between the 1oxyl-3-oxide-imidazoline and phenyl rings are calculated equal to $47.0(1)^{\circ}$ and $32.7(1)^{\circ}$ for molecule A and B, respectively; ii) The alkylated moiety (the radical) and the TTF-based moiety are perpendicular $\left(88.0(1)^{\circ}\right)$ for the molecule $\mathrm{B}$ while this angle is $74.9(1)^{\circ}$ for the molecule A; iii) The twist angle between the pyridine ring and the benzoimidazole fragment is equal to $13.3(1)^{\circ}$ for the molecule A but is twice larger $\left(28.6(1)^{\circ}\right)$ for the molecule $\mathrm{B}$; iv) The TTF core adopts a boat conformation in the molecule A while it is almost planar in the molecule B; v) Finally the two thiopropyl groups are on the same side compared to the plan formed by the TTF core i.e. the side of the radical moiety for molecule A while for the molecule B one thiopropyl group is localized in the plan of the TTF core and the second one is localized on the opposite side of the radical unit. 


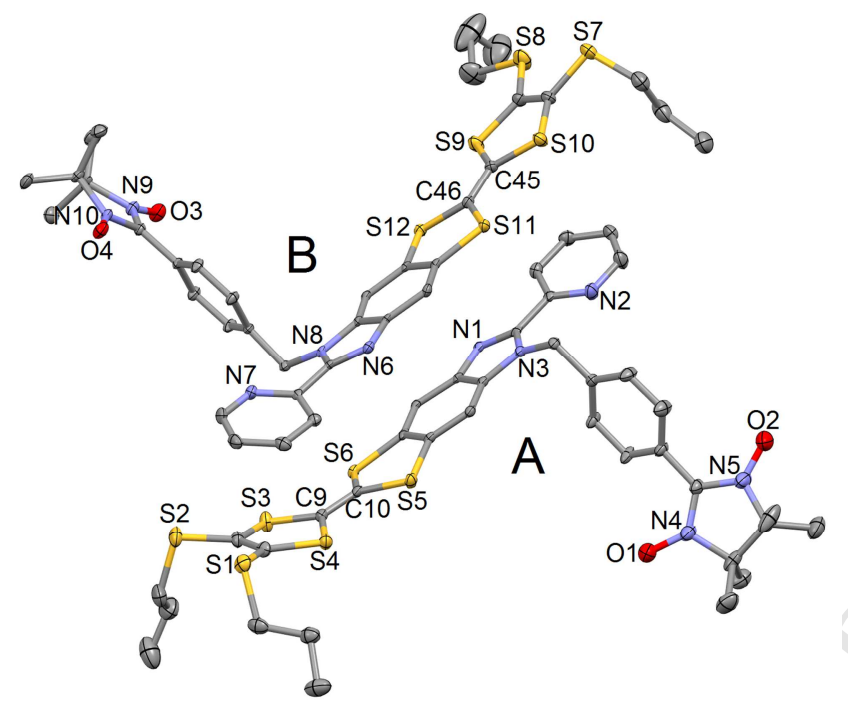

Fig. 1. ORTEP view of 3. Thermal ellipsoids are drawn at $30 \%$ probability. Hydrogen atoms are omitted for clarity.

These differences are imposed by the crystal packing to optimize the interaction between the molecules. The latter reveals the formation of head-to-tail dimers through $\pi-\pi$ stacking between the TTF core and imidazole-2-pyridine (Fig. 2a). In order to optimize the stack, the TTF in boat conformation is associated with the more twisted imidazole-2-pyridine moiety $\left(28.6^{\circ}\right)$ while the planar TTF is associated with the less twisted imidazole-2-pyridine moiety $\left(13.3^{\circ}\right)$.
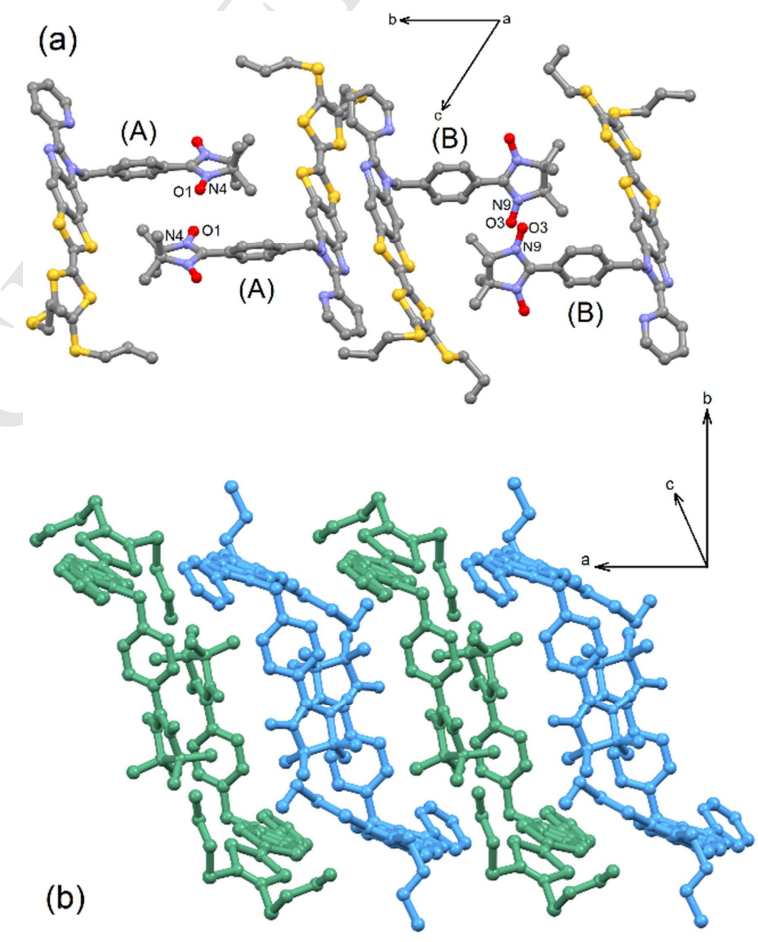
Fig. 2. Crystal packing of $\mathbf{3}$ in the (011) plan (a) and along the $a$ axis with highlights of the A-A (green) and B-B (blue) dimers (b).

The difference between the values for the two other listed angles are a consequence of the optimization of the interaction between the 1-oxyl-3-oxide-4,4,5,5-tetramethylimidazoline radicals. The radical units form two kinds of dimers involving either two molecules A (drawn in green on Fig. 2b) or two molecules B (drawn in blue on Fig. 2b). Several short contacts between the $\mathrm{N}-\mathrm{O}$ groups have been identified with $\mathrm{O} 1 \cdots \mathrm{O} 1=3.545 \AA$, O1 $\cdots \mathrm{N} 4=3.463 \AA$, $\mathrm{N} 4 \cdots \mathrm{N} 4=3.840 \AA$ for the dimer of molecules $\mathrm{A}$ and $\mathrm{O} 3 \cdots \mathrm{O} 3=3.392 \AA, \mathrm{O} 3 \cdots \mathrm{N} 9=3.435 \AA$ and N9...N9 $=3.922 \AA$ for the dimer of molecule B. Then the dimers of A-A and B-B molecules are almost perpendicular and interact together through other relatively short contacts between the $\mathrm{N}-\mathrm{O}$ groups with $\mathrm{O} 1 \cdots \mathrm{O} 4=4.312 \AA, \mathrm{O} 2 \cdots \mathrm{O} 4=4.756 \AA$ and $\mathrm{N} 5 \cdots \mathrm{O} 4=$ $4.862 \AA$. These contacts may have significant consequences on the magnetic behavior of 3 .

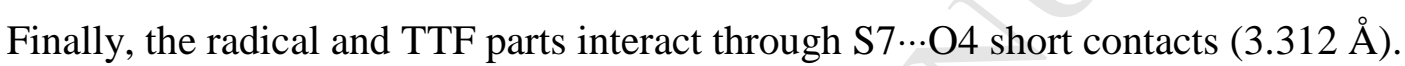

\subsection{Cyclic voltammetry}

The redox properties of compounds 1-3 are investigated by cyclic voltammetry (Fig. 3). The values of the oxidation potentials are listed in Table 2. On the one hand, the cyclic voltammogram for 2 shows one mono-electronic oxidation at $0.85 \mathrm{~V}$ corresponding to the oxidation of the nitroxide radical to the oxoammonium cation[56]. On the other hand, the cyclic voltammogram for 1 shows two mono-electronic oxidations at $0.50 \mathrm{~V}$ for the first oxidation and $0.91 \mathrm{~V}$ for the second oxidation, corresponding to the formation of a radical cation and a dicationic TTF fragment, respectively[39]. Finally, the voltammogram for 3 shows three mono-electronic oxidations at $0.51 \mathrm{~V}$ for the first oxidation, $0.84 \mathrm{~V}$ for the second oxidation and $0.93 \mathrm{~V}$ (Fig. S3) for the third oxidation corresponding to the formation of a radical cation form of the TTF core, the oxoammonium cation and the dicationic form of the TTF fragment, respectively. 


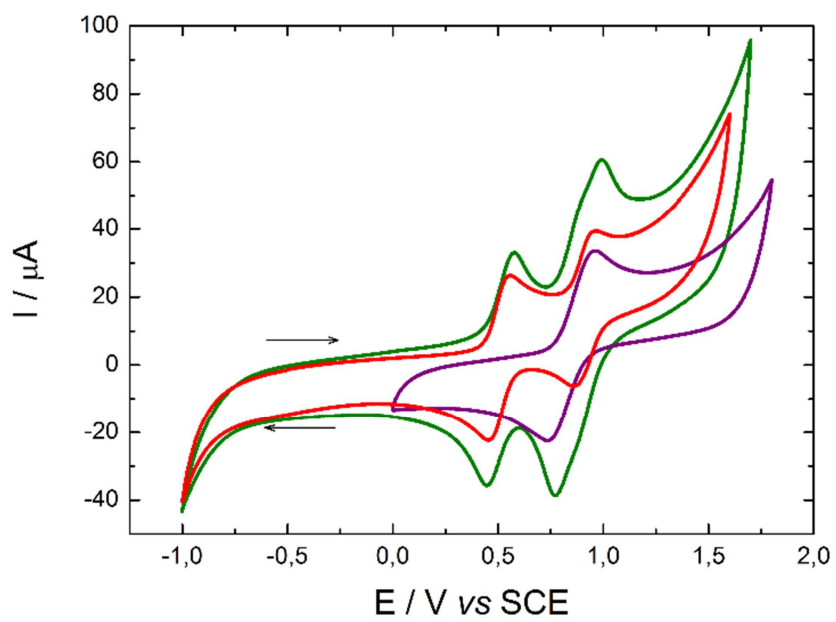

Fig. 3. Cyclic voltammograms of $\mathbf{1}$ (red curve), $\mathbf{2}$ (purple curve) and $\mathbf{3}$ (green curve) in $\mathrm{CH}_{2} \mathrm{Cl}_{2}$ at a scan rate of $100 \mathrm{mV} \cdot \mathrm{s}^{-1}$. The potentials were measured vs. a saturated calomel electrode (SCE) with Pt wires as working and counter electrodes.

The electrochemical properties attest the possibility to i) oxidize the TTF core in the radical cation form maintaining the integrity of the nitronyl nitroxide radical and ii) the reversibility of all the oxidations.

Table 2. Oxidation potentials (V vs SCE, $\mathrm{nBu}_{4} \mathrm{NPF}_{6}, 0.1 \mathrm{M}$ in $\mathrm{CH}_{2} \mathrm{Cl}_{2}$ at $100 \mathrm{mV} \cdot \mathrm{s}^{-1}$ ) of the complexes 1-3.

\begin{tabular}{|l|c|c|c|c|c|c|}
\hline \multirow{2}{*}{} & \multicolumn{2}{|c|}{$\mathrm{E}_{1 / 2}^{1} / \mathrm{V}$} & \multicolumn{2}{c|}{$\mathrm{E}^{2}{ }_{1 / 2} / \mathrm{V}$} & \multicolumn{2}{c|}{$\mathrm{E}^{3}{ }_{1 / 2} / \mathrm{V}$} \\
\cline { 2 - 7 } & ${ }^{O x} \mathrm{E}_{1 / 2}^{1}$ & ${ }^{\operatorname{Red}} \mathrm{E}_{1 / 2}^{1}$ & ${ }^{\mathrm{Ox}} \mathrm{E}_{1 / 2}^{2}$ & ${ }^{\operatorname{Red}} \mathrm{E}^{2}{ }_{1 / 2}$ & ${ }^{\mathrm{Ox}} \mathrm{E}_{1 / 2}^{3}$ & ${ }^{\operatorname{Red}} \mathrm{E}_{1 / 2}^{3}$ \\
\hline $\mathbf{1}$ & 0.56 & 0.45 & $/$ & $/$ & 0.96 & 0.86 \\
$\mathbf{2}$ & $/$ & $/$ & 0.96 & 0.73 & $/$ & $/$ \\
$\mathbf{3}$ & 0.58 & 0.45 & 0.91 & 0.77 & 0.99 & 0.86 \\
\hline
\end{tabular}

\subsection{Magnetic characterizations}

The calculated total spin density distribution of $\mathbf{3}$ is shown in Fig. 4a (see computational details) whereas the Single-Occupied Molecular Orbital (SOMO) is called HOMO- $1 \alpha$ on Fig. 6. The SOMO is essentially located on the 1-oxyl-3-oxide-imidazoline unit with the spin density mainly localized on the O-N-C-N-O chemical bonds of the 1-oxyl3-oxide-imidazoline moiety with partial delocalization on the phenyl ring. Solution room temperature EPR spectroscopy confirms that the radical is localized on the nitronyl nitroxide moiety. The X-band spectrum recorded with a BRUKER EMX spectrophotometer at an 
excitation frequency of $9.468011 \mathrm{GHz}$ of $\mathbf{3}$ measured in toluene at room temperature is shown on Fig. 4b. It features the characteristic signal of a single electron spin ( $g=2.00716)$ coupled to two equivalent ${ }^{14} \mathrm{~N}$ nuclear spins $\left(\mathrm{a}_{\mathrm{N}}=7.44 \mathrm{G}\right)$. This value is in agreement with other reported values for nitroxide radical derivatives [57].
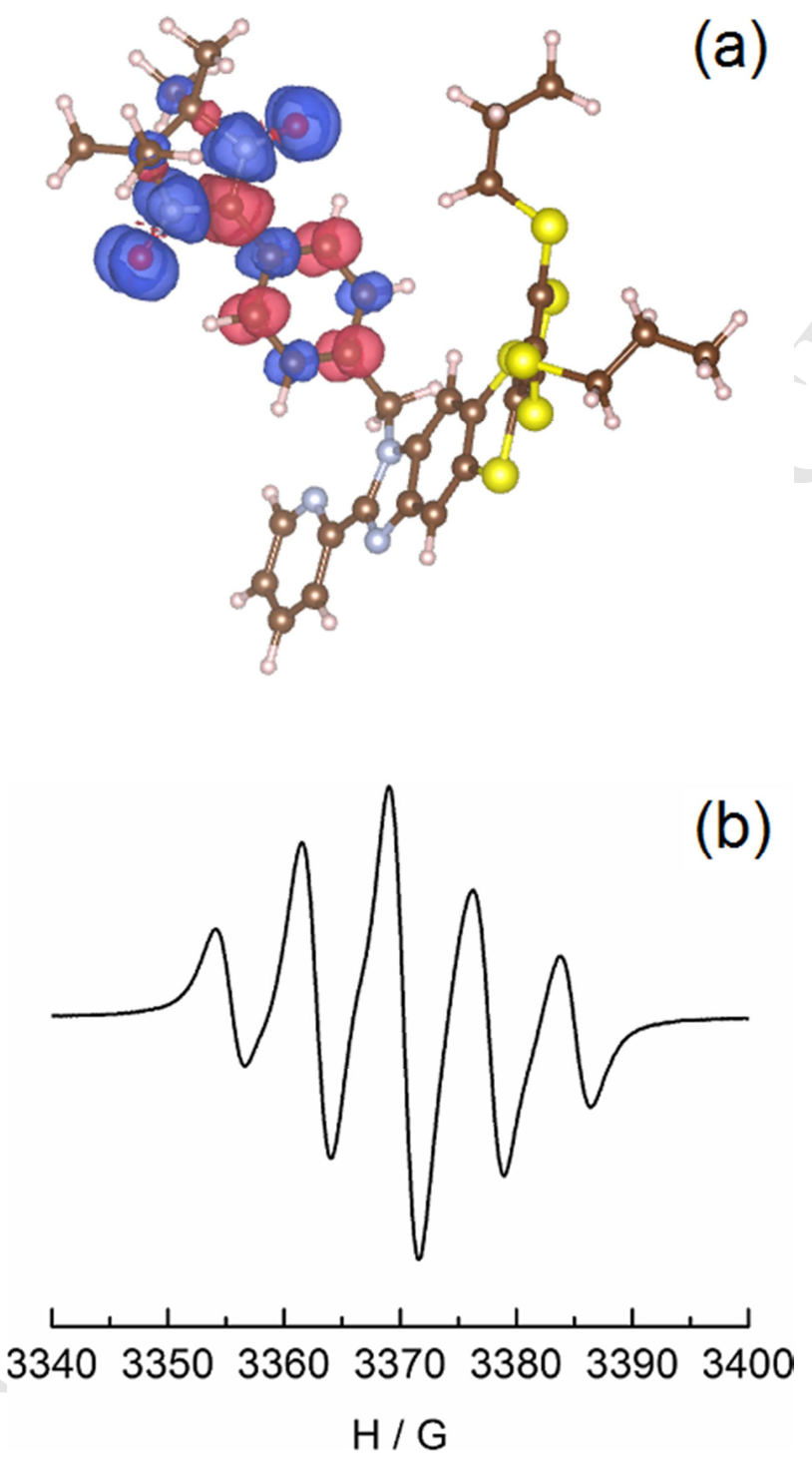

Fig. 4. (a) Spin density distribution with Mulliken analysis spin population (spin density cut off $0.005 \mathrm{e}^{-}$bohr $^{-3}$ ), (b) EPR spectrum at room temperature of 3 in toluene.

\subsection{Absorption spectra}

The UV-visible absorption properties of $\mathbf{3}$ have been studied in $\mathrm{CH}_{2} \mathrm{Cl}_{2}$ solution (Fig. 5). To rationalize the attribution of the experimental absorption bands, TD-DFT calculations were performed on the DFT-optimized geometry (see computational details) of $\mathbf{3}$, following a 
computational strategy already used successfully on other TTF-based systems[21],[60],[61]. The calculated UV-visible absorption spectrum and molecular orbital diagram are shown in Fig. 5 and 6, respectively. The absorption spectrum of $\mathbf{3}$ can be described as the sum of the absorption spectra of $\mathbf{1}$ and $\mathbf{2}$ (Fig. S4). The experimental absorption curve of $\mathbf{3}$ has been decomposed into eight bands (Fig. 5a and Table 3). The calculated UV-visible absorption spectrum for $\mathbf{3}$ reproduces well the experimental curve (Fig. 5a and 5b). The lowest energy band is calculated at the average value of $23177 \mathrm{~cm}^{-1}$ (experimental value $25100 \mathrm{~cm}^{-1}$ ) and attributed to a $\pi-\pi^{*} \mathrm{HOMO}_{\alpha} \rightarrow \mathrm{LUMO}_{\alpha}$ transition which is identified as the Intra-Ligand Charge Transfer (ILCT) from the TTF core to the benzimidazole-2-pyridine acceptor (red deconvolution). The later ILCT is classically observed for the TTF-based ligands especially for the 2-(4,5-(4,5-bis(propylthio)-tetrathiafulvalenyl)-1H-benzimidazol-2-yl)-pyridine molecular skeleton 1[38],[62]. The two other $\mathrm{HOMO}_{\beta} \rightarrow \mathrm{LUMO}_{\beta}$ and $\mathrm{HOMO}_{\beta} \rightarrow \mathrm{LUMO}+1_{\beta}$ transitions were identified as a TTF to Nitronyl nitroxide (NIT) charge transfer (ILCT) (Fig. 5a, Table 3).
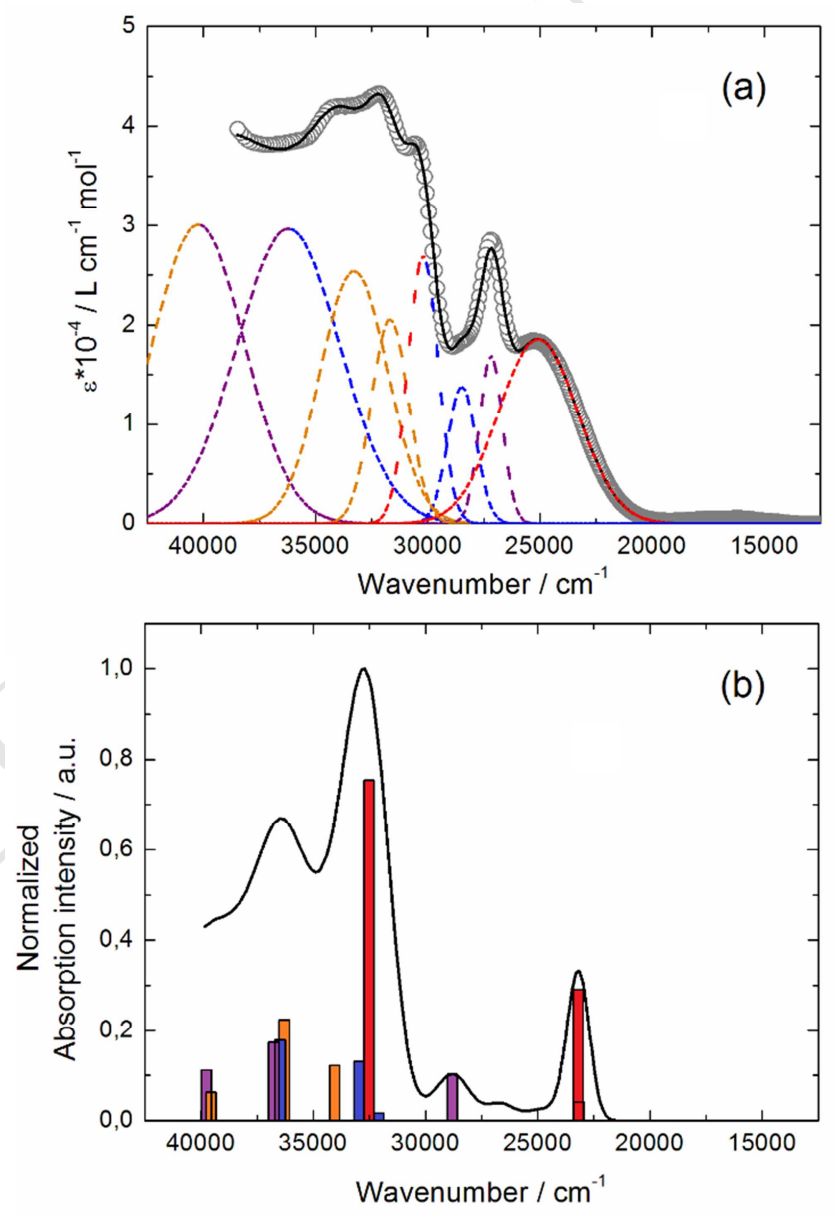

Fig. 5. a) Experimental UV/vis absorption spectrum in solution $\left(c=4 \cdot 10^{-5} \mathrm{M}\right)$ of 3 in $\mathrm{CH}_{2} \mathrm{Cl}_{2}$ (open grey circles), respective Gaussian decompositions (dashed lines) and best fit (full black 
line). b) Theoretical absorption spectrum (black line), the bars represent the main contributions that are listed in Table 3.

Table 3. TD-DFT calculated excitation energies and main contributions of the low-lying electronic transitions for 3. In addition, the charge transfer and the pure intramolecular transitions are reported. ID, IA, INIT, H and L represent the intramolecular TTF (Donor), intramolecular benzimidazole-2-pyridine (bzip, Acceptor) and intramolecular nitronyl nitroxide (NIT) transitions, and the HOMO and LUMO, respectively. Therefore, ILCT stands for Intra-Ligand Charge Transfer. The theoretical values are evaluated at the $\mathrm{PCM}\left(\mathrm{CH}_{2} \mathrm{Cl}_{2}\right)$ PBE0/SVP level of approximation.

\begin{tabular}{|c|c|c|c|c|c|}
\hline $\begin{array}{c}\mathrm{E}_{\exp } \\
\left(\mathrm{cm}^{-1}\right)\end{array}$ & $\begin{array}{l}\mathrm{E}_{\text {theo }} \\
\left(\mathrm{cm}^{-1}\right)\end{array}$ & Osc. & Type & Assignment & Transition \\
\hline 25100 & $\begin{array}{l}23160 \\
23194\end{array}$ & $\begin{array}{l}0.05 \\
0.35\end{array}$ & ILCT & $\begin{array}{l}\pi_{\mathrm{TTF}} \rightarrow \pi *_{\text {NIT }} \\
\pi_{\mathrm{TTF}} \rightarrow \pi{ }^{*} \text { bzip }\end{array}$ & $\begin{array}{c}\mathrm{H}_{\beta} \rightarrow \mathrm{L}_{\beta}(88 \%) \\
\mathrm{H}_{\alpha} \rightarrow \mathrm{L}_{\alpha}(48 \%) \\
\mathrm{H}_{\beta} \rightarrow \mathrm{L}+1_{\beta}(42 \%)\end{array}$ \\
\hline 27200 & 28812 & 0.12 & INIT & $\pi_{\mathrm{NIT}} \rightarrow \pi^{*}{ }_{\mathrm{NIT}}$ & $\begin{array}{l}\mathrm{H}-1_{\alpha} \rightarrow \mathrm{L}_{\alpha}(40 \%) \\
\mathrm{H}-1_{\beta} \rightarrow \mathrm{L}_{\beta}(57 \%)\end{array}$ \\
\hline 28500 & 32080 & 0.02 & IA & $\pi_{\mathrm{NIT}} \rightarrow \pi_{\text {bzip }}^{*}$ & $\begin{array}{c}\mathrm{H}-10_{\alpha} \rightarrow \mathrm{L}+1_{\alpha}(20 \%) \\
\mathrm{H}-10_{\beta} \rightarrow \mathrm{L}+1_{\beta}(10 \%) \\
\mathrm{H}-1_{\beta} \rightarrow \mathrm{L}+1_{\beta}(34 \%)\end{array}$ \\
\hline 30200 & $\begin{array}{l}32525 \\
32954\end{array}$ & $\begin{array}{l}0.90 \\
0.16\end{array}$ & $\begin{array}{c}\text { IA } \\
+ \\
\text { ILCT }\end{array}$ & $\pi_{\text {bzipTTF }} \rightarrow \pi_{\text {bzip }}$ & $\begin{array}{c}\mathrm{H}-3_{\alpha} \rightarrow \mathrm{L}_{\alpha}(32 \%) \\
\mathrm{H}-2_{\alpha} \rightarrow \mathrm{L}_{\alpha}(37 \%) \\
\mathrm{H}-3_{\beta} \rightarrow \mathrm{L}+1_{\beta}(32 \%) \\
\mathrm{H}-2_{\beta} \rightarrow \mathrm{L}+1_{\beta}(38 \%)\end{array}$ \\
\hline 31700 & 34047 & & & $\pi_{\mathrm{TTF}} \rightarrow \pi^{*}{ }_{\mathrm{TTF}}$ & $\begin{array}{c}\mathrm{H}-2_{\alpha} \rightarrow \mathrm{L}+3_{\alpha}(7 \%) \\
\mathrm{H}_{\alpha} \rightarrow \mathrm{L}+6 /+7_{\alpha}(8 / 11 \%) \\
\mathrm{H}-2_{\beta} \rightarrow \mathrm{L}+4_{\beta}(7 \%) \\
\mathrm{H}_{\beta} \rightarrow \mathrm{L}+7 /+8_{\beta} \\
(10 / 13 \%)\end{array}$ \\
\hline 33300 & 36292 & 0.27 & ID & $\pi_{\mathrm{TTF}} \rightarrow \pi^{*} \mathrm{TTF}$ & $\begin{array}{c}\mathrm{H}-2_{\alpha} \rightarrow \mathrm{L}+3_{\alpha}(10 \%) \\
\mathrm{H}_{\alpha} \rightarrow \mathrm{L}+7 /+9_{\alpha}(9 / 9 \%) \\
\mathrm{H}-2_{\beta} \rightarrow \mathrm{L}+4_{\beta}(10 \%) \\
\mathrm{H}_{\beta} \rightarrow \mathrm{L}+8 /+10_{\beta}(9 / 9 \%)\end{array}$ \\
\hline 36200 & $\begin{array}{l}36475 \\
36763 \\
\end{array}$ & $\begin{array}{l}0.21 \\
0.21\end{array}$ & $\begin{array}{c}\stackrel{\text { INIT }}{+} \\
\stackrel{+}{\text { IA/ILCT }} \\
\end{array}$ & $\begin{array}{c}\pi_{\mathrm{NIT}} \rightarrow \pi^{*}{ }_{\text {NIT }} \\
+ \\
\pi_{\text {bzipTTF }} \rightarrow \pi_{\text {bzip }}^{*}\end{array}$ & $\begin{array}{c}\mathrm{H}-5_{\alpha} \rightarrow \mathrm{L}+1_{\alpha}(46 \%) \\
\mathrm{H}-4_{\alpha} \rightarrow \mathrm{L}_{\alpha}(38 \%) \\
\mathrm{H}-4_{\beta} \rightarrow \mathrm{L}+1_{\beta}(29 \%)\end{array}$ \\
\hline 40220 & $\begin{array}{l}39549 \\
39766\end{array}$ & $\begin{array}{l}0.07 \\
0.13\end{array}$ & $\begin{array}{l}\text { ID } \\
\text { INIT }\end{array}$ & $\begin{array}{l}\pi_{\mathrm{TTF}} \rightarrow \pi^{*} \mathrm{TTF} \\
\pi_{\mathrm{NIT}} \rightarrow \pi^{*}{ }_{\mathrm{NIT}}\end{array}$ & $\begin{array}{c}\mathrm{H}-3_{\alpha} \rightarrow \mathrm{L}+2_{\alpha}(15 \%) \\
\mathrm{H}-2_{\alpha} \rightarrow \mathrm{L}+2_{\alpha}(16 \%) \\
\mathrm{H}-3_{\beta} \rightarrow \mathrm{L}+3_{\beta}(15 \%) \\
\mathrm{H}-2_{\beta} \rightarrow \mathrm{L}+3_{\beta}(18 \%) \\
\mathrm{H}-16_{\alpha} \rightarrow \mathrm{L}+1_{\alpha}(12 \%) \\
\mathrm{H}-5_{\alpha} \rightarrow \mathrm{L}+1_{\alpha}(7 \%) \\
\mathrm{H}-11_{\beta} \rightarrow \mathrm{L}+2_{\beta}(7 \%)\end{array}$ \\
\hline
\end{tabular}

The next absorption band clearly comes from the nitronyl nitroxide contribution (Fig. S4) and it has been effectively identified as a pure $\pi-\pi^{*}$ NIT to NIT excitation (HOMO- $1_{\alpha} \rightarrow$ $\mathrm{LUMO}_{\alpha}$ and HOMO- $1_{\beta} \rightarrow \mathrm{LUMO}_{\beta}$ ) centered at $27200 \mathrm{~cm}^{-1}$ (calculated at $28812 \mathrm{~cm}^{-1}$ ) 
(purple deconvolution) (Table 3). The next four absorption deconvolution bands were calculated at $32080 \mathrm{~cm}^{-1}$, average value of $32740 \mathrm{~cm}^{-1}, 34047 \mathrm{~cm}^{-1}$ and $36292 \mathrm{~cm}^{-1}$ and mainly assigned to intra-benzimidazole-2-pyridine moiety (IA) followed by intra-TTF (ID) transitions.

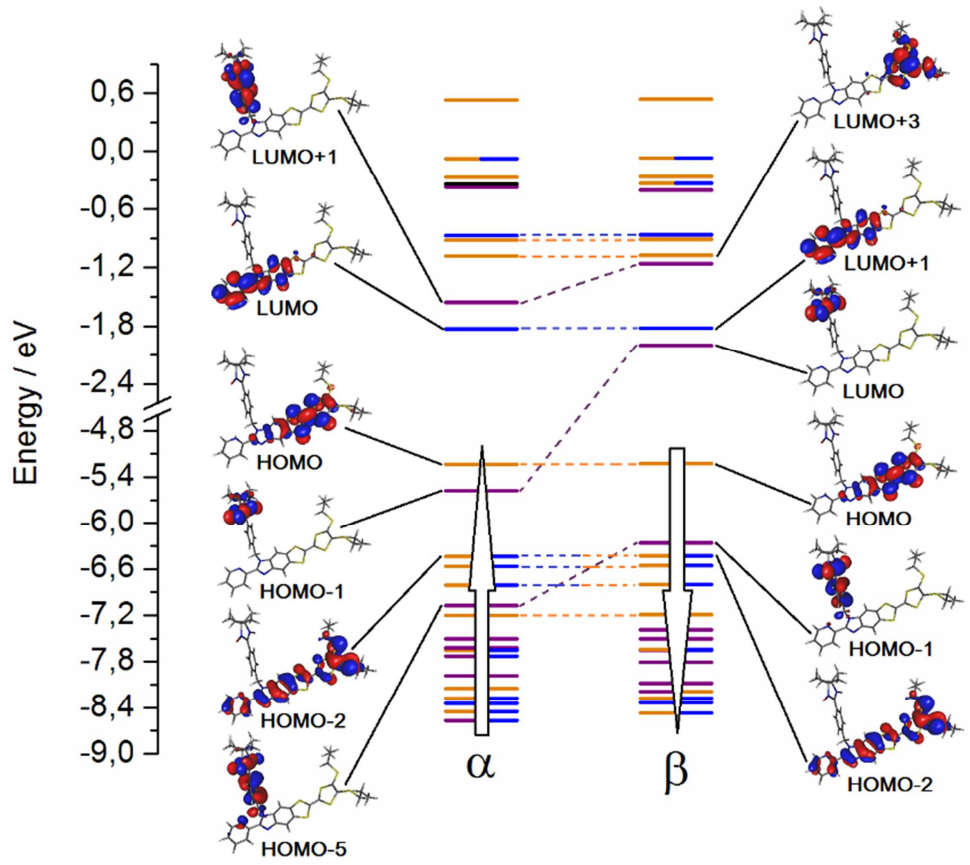

Fig. 6. MO diagram of $\mathbf{3}$.

The two highest energy bands of the absorption spectrum are assigned to a mixture of a new intra-NIT excitation (HOMO- $5_{\alpha} \rightarrow \mathrm{LUMO}+1_{\alpha}$ ) with additional IA and ID contributions (Table 3). One can notice that the alkylation of the molecular skeleton 1 with an organic radical moiety leads to a significant change in the low-energy part of the absorption spectrum compared to what is seen for other alkylated based-TTF ligands. Indeed the alkylating group has been reported to have negligible effect on the low-energy part of the absorption spectrum when this group is the 2-pyridine[37]. When the alkylating group is a more $\pi$-extended moiety such as the dimethyl-2,2'-bipyridine or di-(pyrazol-1-yl)-4-pyridyl group, a significant effect on the higher-energy part of the spectrum $\left(35000-38000 \mathrm{~cm}^{-1}\right)$ is observed[40].

\subsection{Emission spectra}

The emission and excitation spectra of $\mathbf{3}$ are represented in Fig. 7, S5-S7. At $77 \mathrm{~K}$ in $\mathrm{CH}_{2} \mathrm{Cl}_{2}$ frozen solution, the photo-excitation of $\mathbf{3}$ at $27027 \mathrm{~cm}^{-1}(370 \mathrm{~nm})$ in the $\pi-\pi^{*}$ $\mathrm{HOMO}_{-} 1_{\alpha} \rightarrow \mathrm{LUMO}_{\alpha}$ and HOMO- ${ }_{\beta} \rightarrow \mathrm{LUMO}_{\beta}$ transitions (NIT to NIT transitions, see 
absorption properties section) results in a visible/near-infrared and structured emission with several maxima between 18000 and $12000 \mathrm{~cm}^{-1}$ (Fig. 7a).
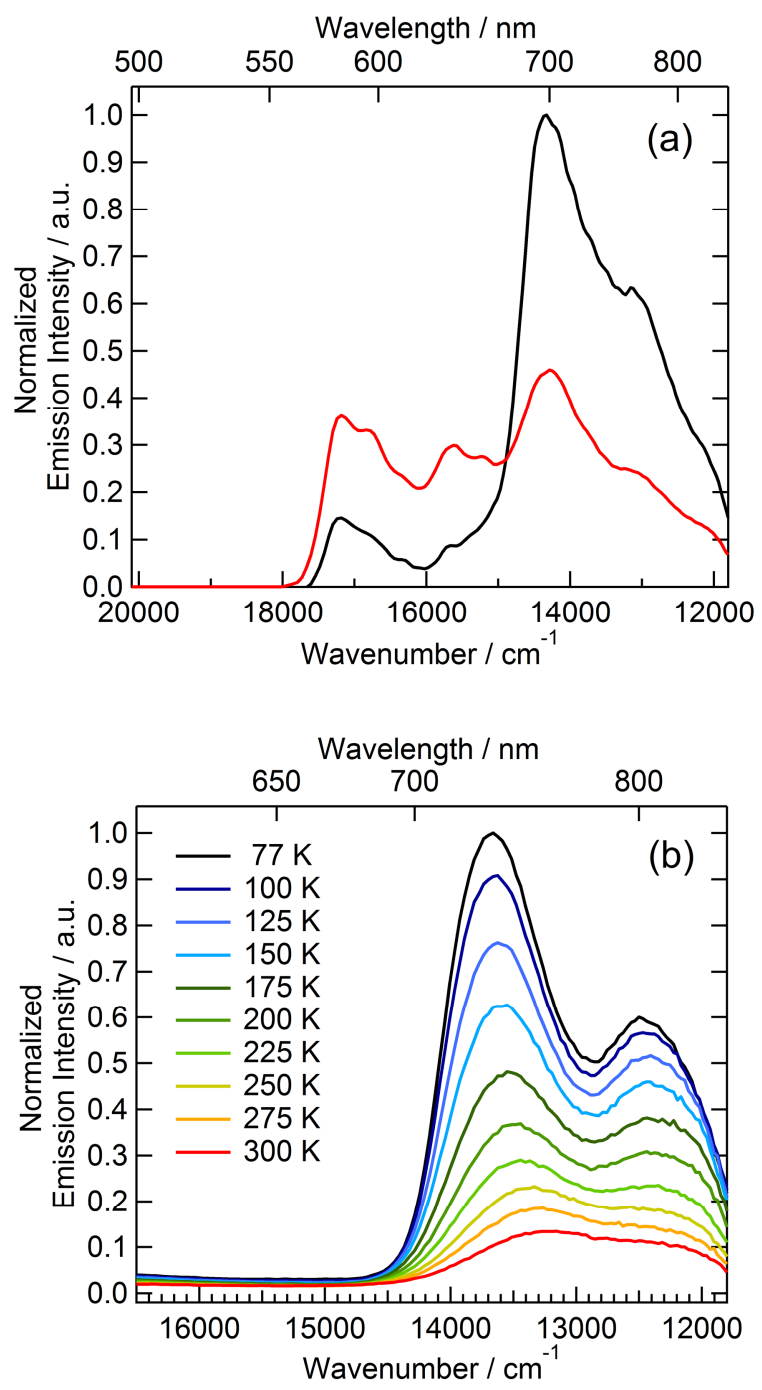

Fig. 7. (a) Solution $\left(\lambda_{\mathrm{ex}}=27027 \mathrm{~cm}^{-1}(370 \mathrm{~nm})\right.$ in the $\mathrm{H}-1_{\alpha} \rightarrow \mathrm{L}_{\alpha}$ and $\mathrm{H}-1_{\beta} \rightarrow \mathrm{L}_{\beta} \pi \rightarrow \pi^{*}$ intraNIT excitation for black curve) and $\left(\lambda_{\mathrm{ex}}=23810 \mathrm{~cm}^{-1}(420 \mathrm{~nm})\right.$ in the $\mathrm{H}_{\alpha} \rightarrow \mathrm{L}_{\alpha}$ and $\mathrm{H}_{\beta} \rightarrow \mathrm{L}+1_{\beta}$ ILCT for red curve) luminescence spectrum of 3 in $\mathrm{CH}_{2} \mathrm{Cl}_{2}\left(\mathrm{C}=1.9 \times 10^{-5} \mathrm{M}\right)$ at $77 \mathrm{~K}$. (b) Solid-state $\left(\lambda_{\mathrm{ex}}=27027 \mathrm{~cm}^{-1}(370 \mathrm{~nm})\right)$ luminescence spectra of $\mathbf{3}$ in the $77-300 \mathrm{~K}$ temperature range.

By analogy with previous reports, the high-energy maxima localized in frozen solution at 17180, 16700, 16300 and $15700 \mathrm{~cm}^{-1}$ can be attributed to the molecular skeleton 1 (17035 and $15350 \mathrm{~cm}^{-1}$ )[39]. Consequently, it can be associated to a phosphorescence signal. Moreover, the most intense signal at lower energy with maxima localized at 14350, 13900, 13700,13050 and $12200 \mathrm{~cm}^{-1}$ is attributed to the emission of the nitronyl nitroxide radical. It is worth noticing that light irradiation in the lowest-energy ILCT $\left(23810 \mathrm{~cm}^{-1}\right)$ which is 
attributed to $\pi_{\mathrm{TTF}} \rightarrow \pi^{*}$ NIT $\quad \mathrm{HOMO}_{\beta} \rightarrow \mathrm{LUMO}_{\beta}$ and $\pi_{\mathrm{TTF}} \rightarrow \pi^{*}$ bzip $\mathrm{HOMO}_{\alpha} \rightarrow \mathrm{LUMO}_{\alpha}$ and $\mathrm{HOMO}_{\beta} \rightarrow \mathrm{LUMO}+1_{\beta}$ ILCT (Table 3), significantly change the ratio between the two emission signals (Fig. 7). In other words, the intensity ratio of the emissions of NIT radical and TTF-based molecular skeleton is dependent of the contribution of them in the irradiated absorption band. As a consequence $\mathbf{3}$ can be described as a tunable multi-emissive ligand at low temperature in $\mathrm{CH}_{2} \mathrm{Cl}_{2}$ solution. Such multi-emissive behavior has already been observed in another TTF-based ligand due to the weak internal conversion between the excited singlet states on the NIT radical and the molecular TTF-based skeleton[63].

The emission properties of $\mathbf{3}$ have been also studied in solid-state between 77 and 300 $\mathrm{K}$. At low temperature, only the emission of the radical moiety is detected with a thinner signal than in solution nevertheless with two observable maxima at $13660 \mathrm{~cm}^{-1}\left(\mathrm{E}_{\max 1}\right)$ and $12500 \mathrm{~cm}^{-1}\left(E_{\max 2}\right)$. At $77 \mathrm{~K}$, the maximum $E_{\max 1}$ in the solid-state spectrum is shifted by -700 $\mathrm{cm}^{-1}$ by comparison with the maximum observed in the frozen solution spectrum. This difference comes from the disappearance of the interactions between the molecular entities leading to perfectly independent molecules in solution. Unfortunately the room temperature emission either in solid or liquid state is too weak to determine a reliable quantum yield.

On the solid-state, by lowering the temperature, the intensity of the radical emission decreases by a factor of 6 and a gradual redshift of the maxima of approximately $-1.8 \mathrm{~cm}^{-1} / \mathrm{K}$ $\left(-400 \mathrm{~cm}^{-1}\right)$ and $-0.9 \mathrm{~cm}^{-1} / \mathrm{K}\left(-200 \mathrm{~cm}^{-1}\right)$ for $E_{\max 1}$ and $E_{\max 2}$, respectively (Fig. 7b). These trends are in agreement with what was observed on nitronyl nitroxide (NIT) compounds either uncoordinated or coordinated by lanthanide ions [64].

\section{Conclusions}

In conclusion, the synthesis of one of the rare examples of compounds combining both redox active tetrathiafulvalene (TTF) and nitronyl nitroxide (NIT) moieties is presented. The molecular skeleton 2-(4,5-(4,5-bis(propylthio)-tetrathiafulvalenyl)-1H-benzimidazol-2yl)-pyridine 1 was alkylated with the 4-bromomethylbenzo(1-oxyl-3-oxide-4,4,5,5tetramethylimidazolin-2-yl) organic radical 2 leading to the formation of 2-\{1[methylbenzo(1-oxyl-3-oxide-4,4,5,5-tetramethylimidazoline)]-4,5-[4,5-bis(propylthio)tetrathiafulvalenyl]-1H-benzimidazol-2-yl pyridine compound 3. This latter compound can be described as a TTF-based conjugated donor-acceptor dyad decorated with a radical acceptor or as a donor-acceptor-radical triad. After alkylation of the TTF-based molecular skeleton, $\mathbf{3}$ keeps the paramagnetic behavior brought by the radical moiety. $\mathbf{3}$ presents very 
exciting and rich electrochemistry and photo-physical properties. Both TTF and NIT can be reversibly oxidized and cyclic voltammetry highlights the possibility to stabilize the radical cation form of the TTF core without oxidizing the NIT radical. The alkylating radical unit strongly contributes to the absorption spectrum with electronic communication between the TTF core and NIT unit, thus leading to Intra-Ligand Charge Transfer (ILCT). Light irradiation of $\mathbf{3}$ highlights the tunable multi-emissive behavior of $\mathbf{3}$ in $\mathrm{CH}_{2} \mathrm{Cl}_{2}$ solution with a complex visible/near-infrared phosphorescence coming from the both NIT and TTF-based skeleton.

The TTF-based donor-acceptor-radical triad could pave the road to multifunctional coordination complexes with electronic conductivity and single-molecule/ single-chain magnet behaviors.

\section{Acknowledgments}

This work was supported by Région Bretagne, Rennes Métropole, CNRS, Université de Rennes 1, INSA of Rennes, FEDER and the ANR (ANR-13-BS07-0022-01). H.D. thanks the Algerian ministry of education and research for financial support during her stay in Rennes. B.L.G. thanks the French GENCI/IDRIS-CINES center for high-performance computing resources.

\section{References}

[1] Spaldin N A, Fiebig M. Materials science. The renaissance of magnetoelectric multiferroics. Science 2005; 309: 391-392.

[2] Eerenstein W, Mathur N D, Scott J F. Multiferroic and magnetoelectric materials. Nature 2006; 442: 759-765.

[3] Train C, Gheorghe R, Krstic V, Chamoreau L M, Ovanesyan N S, Rikken G L J A, Gruselle M, Verdaguer M. Strong magneto-chiral dichroism in enantiopure chiral ferromagnets. Nature Materials 2008; 7: 729-734.

[4] Ferraris J, Cowan D O, Walatka V, Perlstein J H. Electron transfer in a new highly conducting donor-acceptor complex. J. Am. Chem. Soc. 1973; 95: 948-949.

[5] Pointillart F, Golhen S, Cador O, Ouahab, L. Paramagnetic 3d coordination complexes involving redox-active tetrathiafulvalene derivatives: an efficient approach 
to elaborate multi-properties materials. Dalton Trans. 2013; 42: 1946-1960 and references therein.

[6] Hu L, Liu W, Li C-H, Zhou X-H, Zuo J-L. Iron(II) Complexes Based on $\pi$ Conjugated Terpyridine Ligands with Tetrathiafulvalene or Its Radical Analogue. Eur. J. Inorg. Chem. 2013: 6037-6048.

[7] Xiao X, Pan W, Wang Z, Shen Z, Shen L, Fang J, Gao H, Li X, Fujiwara H. Selfordering of organic-metal hybrid microstructures based on tetrathiafulvalene derivatives. Synthetic Metals 2014; 189: 42-46.

[8] Pointillart F, Golhen S, Cador O, Ouahab L. 3d and 4d coordination complexes and coordination polymers involving electroactive tetrathiafulvalene containing ligands. C. R. Chimie 2013; 16: 679-688.

[9] Douib H, Pointillart F, Lefeuvre B, Golhen B, Golhen S, Cador O, Le Guennic B, Gouasmia A, Ouahab L. Structural and Physical Investigations of Coordination Complexes Involving Pyridylethylenedithio-tetrathiafulvalene Ligands decorated with cyano-ethylsulfanyl/-selenanyl moieties. Eur. J. Inorg. Chem. 2016: 5630-5639.

[10] Pointillart F, Le Gal Y, Golhen S, Cador O, Ouahab L. First Paramagnetic 4d Transition-Metal Complex with Redox-Active Tetrathiafulvalene Derivative, $\left[\mathrm{Ru}(\right.$ salen $\left.)\left(\mathrm{PPh}_{3}\right)(\mathrm{TTF}-\mathrm{CH}=\mathrm{CH}-\mathrm{Py})\right]\left(\mathrm{BF}_{4}\right) \quad\left[\right.$ salen $^{2-} \quad=\quad \mathrm{N}, \mathrm{N}^{\prime}-$ Ethan-1,2diylbis(salicylidenamine), $\mathrm{PPh}_{3}=$ Triphenylphosphine, TTF-CH=CH-Py $=4-(2-$ Tetrathiafulvalenylethenyl)pyridine]. Inorg. Chem. 2008; 47: 9730-9732.

[11] Cui H, Otsuka, T, Kobayashi A, Takeda N, Ishikawa M, Misaki Y, Kobayashi H. Structural, electrical, and magnetic properties of a series of molecular conductors based on BDT-TTP and lanthanoid nitrate complex anions (BDT-TTP = 2,5-bis(1,3dithiol- 2-ylidene)-1,3,4,6-tetrathiapentalene). Inorg. Chem. 2003; 42: 6114-6122 and references therein.

[12] Pointillart F, Le Guennic B, Cador O, Maury O, Ouahab L. Lanthanide Ion and Tetrathiafulvalene-Based Ligand as a "Magic" Couple toward Luminescence, Single Molecule Magnets, and Magnetostructural Correlations. Acc. Chem. Res. 2015; 48: 2835-2842 and reference therein.

[13] Tanaka H, Kobayashi H, Kobayashi A, Cassoux P. Superconductivity, Antiferromagnetism, and Phase Diagram of a Series of Organic Conductors: $\lambda$ $(\mathrm{BETS})_{2} \mathrm{Fe}_{\mathrm{x}} \mathrm{Ga}_{1-\mathrm{x}} \mathrm{Br}_{\mathrm{y}} \mathrm{Cl}_{4-\mathrm{y}}$. Adv. Mater. 2000; 12: 1685-1689. 
[14] Uji S, Shinagawa H, Terashima T, Terakura C, Yakabe T, Terai Y, Tokumoto M, Kobayashi A, Tanaka H, Kobayashi H. Magnetic-field-induced superconductivity in a two-dimensional organic conductor. Nature 2001; 410: 908-910.

[15] Mitsumoto K, Nishikawa H, Newton N G, Oshio H. Encapsulation controlled single molecule magnetism in tetrathiafulvalene-capped cyanide-bridged cubes. Dalton Trans. 2012; 41: 13601-13608.

[16] Pointillart F, Le Gal Y, Golhen S, Cador O, Ouahab L. Single-Molecule Magnet Behaviour in a Tetrathiafulvalene-Based Electroactive Antiferromagnetically Coupled Dinuclear Dysprosium(III) Complex. Chem. Eur. J. 2011; 17: 10397-10404.

[17] Pointillart F, Le Guennic B, Golhen S, Cador O, Ouahab L. Slow magnetic relaxation in radical cation tetrathiafulvalene-based lanthanide(III) dinuclear complexes. Chem. Commun. 2013; 49: 11632-11634.

[18] Gao F, Zhang X-M, Cui L, Deng K, Zeng Q-D, Zuo J-L. TetrathiafulvaleneSupported Triple-Decker Phthalocyaninato Dysprosium(III) Complex: Synthesis, Properties and Surface Assembly. Scientific Reports 2014; 4: 5928-5935.

[19] Pointillart F, Le Guennic B, Golhen S, Cador O, Maury O, Ouahab L. A redox-active luminescent ytterbium based single molecule magnet. Chem. Commun. 2013; 49: 615-617.

[20] Soussi K, Jung J, Pointillart F, Le Guennic, Lefeuvre B, Golhen S, Cador O, Guyot Y, Maury O, Ouahab L. Magnetic and photo-physical investigations into Dy ${ }^{\mathrm{III}}$ and $\mathrm{Yb}^{\mathrm{III}}$ complexes involving tetrathiafulvalene ligand. Inorg. Chem. Front. 2015; 2: $1105-$ 1117.

[21] Lorcy D, Bellec N, Fourmigué M, Avarvari N. Tetrathiafulvalene-based group XV ligands: Synthesis, coordination chemistry and radical cation salts. Coord. Chem. Rev. 2009; 253, 1398-1438.

[22] Pop F, Avarvari N. Covalent non-fused tetrathiafulvalene-acceptor systems. Chem. Commun. 2016; 52: 7906-7927.

[23] Nakazaki J, Matsushita M M, Izuoka A, Sugawara T. Novel Spin-Polarized TTF Donors Affording Ground State Triplet Cation Diradicals. Tetrahedron Letters 1999; 40: 5027-5030.

[24] Kumai R, Matsushita M M, Izuoka A, Sugawara T. Intramolecular Exchange Interaction in a Novel Cross-Conjugated Spin System Composed of $\pi$-Ion Radical and Nitronyl Nitroxide. J. Am. Chem. Soc. 1994; 116: 4523-4524. 
[25] Komatsu H, Mogi R, Matsushita M M, Miyagi T, Kawada Y, Sugawara T. Synthesis and properties of TSF-based spin-polarized donor. Polyhedron 2009; 28: 1996-2000.

[26] Komatsu H, Matsushita M M, Yamamura S, Sugawara Y, Susuki K, Sugawara T. Influence of Magnetic Field upon the Conductance of a Unicomponent Crystal of a Tetrathiafulvalene-Based Nitronyl Nitroxide. J. Am. Chem. Soc. 2010; 132: 45284529.

[27] Matsuoka F, Yamashita Y, Kawakami T, Kitagawa Y, Yoshioka Y, Yamaguchi K. Theoretical investigation on the magnetic interaction of the tetrathiafulvalene-nitronyl nitroxide stacking model: possibility of organic magnetic metals and magnetic superconductors. Polyhedron 2001; 20: 1169-1176.

[28] A. Latif I, Singh V P, Bhattacharjee U, Panda A, N. Datta S. Very Strongly Ferromagnetically Coupled Diradicals from Mixed Radical Centers. II. Nitronyl Nitroxide Coupled to Tetrathiafulvalene via Spacers. J. Phys. Chem. A 2010; 114: 6648-6656.

[29] Saha A, A. Latif I, N. Datta S. Photoswitching Magnetic Crossover in Organic Molecular Systems. J. Phys. Chem. A 2011; 115: 1371-1379.

[30] Polo V, Alberola A, Andres J, Anthony J, Pilkington M. Towards understanding of magnetic interactions within a series of tetrathiafulvalene- $\pi$ conjugated-verdazyl diradical cation system: a density functional theory study. Phys. Chem. Chem. Phys. 2008; 10: 857-864.

[31] Venneri S, Wilson J, M. Rawson J, Pilkington M. Structural, Magnetic and DFT studies on a Charge-Transfer Salt of a Tetrathiafulvalenepyridyl-(1,5-diisopropyl) verdazyl Diradical Cation. ChemPlusChem 2015; 80: 1624-1633.

[32] Guasch J, Grisanti L, Lloveras V, Vidal-Gancedo J, Souto M, C. Morales D, Vilaseca M, Sissa C, Painelli A, Ratera I, Rovira C, Veciana J. Induced Self-Assembly of a Tetrathiafulvalene-Based Open-Shell Dyad through Intramolecular Electron Transfer. Angew. Chem. Int. Ed. 2012; 51: 11024-11028.

[33] Guash J, Grisanti L, Souto M, Lloveras V, Vidal-Gancedo J, Ratera I, Painelli A, Rovira C, Veciana J. Intra- and intermolecular Charge Transfer in Aggregates of tetrathiafulvalene-Triphenylmethyl Radical Derivatives in Solution. J. Am. Chem. Soc. 2013; 135: 6958-6967.

[34] Souto M, Guasch J, Lloveras V, Mayorga P, T. Lopez Navarrete J, Casado J, Ratera I, Rovira C, Painelli A, Veciana J. Thermomagnetic Molecular System Based on TTF- 
PTM Radical: Switching the Spin and Charge Delocalization. J. Phys. Chem. Lett. 2013; 4: 2721-2726.

[35] Souto M, C. Morales D, Guasch J, Ratera I, Rovira C, Painelli A, Veciana J. Intramolecular electron transfer and charge delocalization in bistable donor-acceptor systems based on perchlorotriphenylmethyl radicals linked to ferrocene and tetrathiafulvalene units. J. Phys. Org. Chem. 2014; 27: 465-469.

[36] Souto M, V. Solano M, Jensen M, Bendixen D, Delchiaro F, Girlando A, Painelli A, O. Jeppesen J, Rovira C, Ratera I, Veciana J. Self-Assembled Architectures with Segregated Donor and Acceptor Units of a Dyad Besed on a Monopyrrolo-Annulated TTF-PTM Radical. Chem. Eur. J. 2015; 21: 8816-8825.

[37] Jia C-Y, Liu S-X, Tanner C, Leiggener C, Sanguinet L, Levillain E, Leutwyler S, Hauser A, Decurtins S. A redox-active tri-star molecule: merging of TTF and HAT chemistry. Chem. Commun. 2006: 1878-1880.

[38] Jia C, Liu S-X, Tanner C, Leiggener C, Neels A, Sanguinet L, Levillain E, Leutwyler S, Hauser A, Decurtins S. An Experimental and Computational Study on Intramolecular Charge Transfer: A Tetrathiafulvalene-Fused Dipyridophenazine Molecule. Chem. Eur. J. 2007; 13: 3804-3812.

[39] Cosquer G, Pointillart F, Jung J, Le Guennic B, Golhen S, Cador O, Guyot Y, Brenier A, Maury O, Ouahab L. Alkylation Effects in Lanthanide Complexes Involving tetrathiafulvalene Chromophores: Experimental and Theoretical Correlation between Magnetism and Near-Infrared Emission. Eur. J. Inorg. Chem. 2014: 69-82.

[40] Speed S, Feng M, Fernandez Garcia G, Pointillart F, Lefeuvre B, Riobé F, Golhen S, Le Guennic B, Totti F, Guyot Y, Cador O, Maury O, Ouahab L. Investigations of Lanthanide complexes involving multichelating TTF-based ligands. Inorg. Chem. Front. DOI: 10.1039/c6qi00546b.

[41] Pointillart F, Guizouarn T, Lefeuvre B, Golhen S, Cador O, Ouahab L. Rational Design of a Lanthanide-Based Complex Featuring Different Single-Molecule Magnets. Chem. Eur. J. 2015; 21: 16929-16934.

[42] Shimono S, Tamura R, Ikuma N, Takimoto T, Kawame N, Tamada O, Sakai N, Matsuura H, Yamauchi J. Preparation and Characterization of New Chiral Nitronyl Nitroxides Bearing a Stereogenic Center in the Imidazolyl Framework. J. Org. Chem. 2004; 69: 475-481.

[43] Rajca A., Pink M, Mukherjee S, Rajca S, Das K. 1,3-Alternate calix[4]arene nitronyl nitroxide tetraradical and diradical: synthesis, X-ray crystallography, paramagnetic 
NMR spectroscopy, EPR spectroscopy, and magnetic studies. Tetrahedron 2007; 63: 10731-10742.

[44] K. Praveen V, Yamamoto Y, Fukushima T, Tsunobuchi Y, Nakabayashi K, Ohkoshi S-I, Kato K, Takata M, Aida T. Translation of the assembling trajectory by preorganization: a study of the magnetic properties of 1D polymeric unpaired electrons immobilized on a discrete nanoscopic scaffold. Chem. Commun. 2015; 51: 1206-1209.

[45] Sheldrick G M. SHELXT-Integrated space-group and crystal-structure determination. Acta Crystallogr., Sect. A 2015; 71: 3-8.

[46] Sheldrick G M. Crystal structure refinement with SHELXL. Acta Crystallogr. Sect. C $2015 ; 71: 3-8$.

[47] Frisch M J, Trucks G W, Schlegel H B, Scuseria G E, Robb M A, Cheeseman J R, Scalmani G, Barone V, Mennucci B, Petersson G A, Nakatsuji H, Caricato M, Li X, Hratchian H P, Izmaylov A F, Bloino J, Zheng G, Sonnenberg J L, Hada M, Ehara M, Toyota K, Fukuda R, Hasegawa J, Ishida M, Nakajima T, Honda Y, Kitao O, Nakai H, Vreven T, Montgomery Jr. J A, Peralta J E, Ogliaro F, Bearpark M, Heyd J J, Brothers E, Kudin K N, Staroverov V N, Keith T, Kobayashi R, Normand J, Raghavachari K, Rendell A, Burant J C, Iyengar S S, Tomasi J, Cossi M, Rega N, Millam J M, Klene M, Knox J E, Cross J B, Bakken V, Adamo C, Jaramillo J, Gomperts R, Stratmann R E, Yazyev O, Austin A J, Cammi R, Pomelli C, Ochterski J W, Martin R L, Morokuma K, Zakrzewski V G, Voth G A, Salvador P, Dannenberg J J, Dapprich S, Daniels A D, Farkas O, Foresman J B, Ortiz J V, Cioslowski J, Fox D J Gaussian 09 Revision D.01, Gaussian Inc., Wallingford CT, 2013.

[48] Perdew J P, Burke K, Ernzerhof M. Generalized Gradient Approximation Made Simple. Phys. Rev. Lett. 1996; 77: 3865-3868.

[49] Adamo C, Barone V. Toward reliable density functional methods without adjustable parameters: The PBE0 model. J. Chem. Phys. 1999; 110: 6158-6170.

[50] Weigend F, Ahlrichs, R. Balanced basis sets of split valence, triple zeta valence and quadruple zeta valence quality for $\mathrm{H}$ to $\mathrm{Rn}$ : Design and assessment of accuracy. Phys. Chem. Chem. Phys. 2005; 7: 3297-3305.

[51] Tomasi J, Mennucci B, Cammi R. Quantum Mechanical Continuum Solvation Models. Chem. Rev. 2005; 105: 2999-3093.

[52] Cossi M, Barone V. Time-dependent density functional theory for molecules in liquid solutions. J. Chem. Phys. 2001; 115: 4708-4717. 
[53] Improta R, Barone V, Scalmani G, Frisch M J. A State-Specific Polarizable Continuum Model Time Dependent Density Functional Theory Method for Excited State Calculations in Solution. J. Chem. Phys. 2006, 125, 054103-054109.

[54] Allouche, A.-R. Gabedit-A graphical user interface for computational chemistry solfwares. J. Comput. Chem. 2011, 32, 174-182.

[55] Momma K, Izumi F. VESTA 3 for three-dimensional visualization of crystal, volumetric and morphology data. J. Appl. Crystallogr. 2011; 44: 1272-1276.

[56] Budnikova Y G, Gryaznova T V, Kadirov M K, Tret'yakov E V, Kholin K V, Ovcharenko V I, Sagdeev R Z, Sinyashin O G. Electrochemistry of nitronyl and imino nitroxides. Russ. J. Phys. Chem. 2009; 83: 1976-1980.

[57] Osiecki J H, Ullman E F. Studies of free radicals. I. .alpha.-Nitronyl nitroxides, a new class of stable radicals. J. Am. Chem. Soc. 1968; 90: 1078-1079.

[58] Boocock D G B, Darcy R, Ullman E F. Studies of free radicals. II. Chemical properties of nitronylnitroxides. A unique radical anion. J. Am. Chem. Soc. 1968; 90: 5945-5946.

[59] Ullman E F, Osiecki J H, Boocock D G B, Darcy R. Stable free radicals. X. Nitronyl nitroxide monoradicals and biradicals as possible small molecule spin labels. J. Am. Chem. Soc. 1972; 94: 7049-7059.

[60] Pointillart F, Jung J, Berraud-Pache R, Le Guennic B, Dorcet V, Golhen S, Cador O, Maury O, Guyot Y, Decurtins S, Liu S-X, Ouahab L. Luminescence and SingleMolecule Magnet Behavior in Lanthanide Complexes Involving a tetrathiafulvaleneFused Dipyridophenazine Ligand. Inorg. Chem. 2015; 54: 5384-5397.

[61] Cosquer G, Pointillart F, Le Guennic B, Le Gal Y, Golhen S, Cador O, Ouahab L. 3d4f Heterobimetallic Dinuclear and tetranuclear Complexes Involving Tetrathiafulvalene as Ligands: X-ray Structures and Magnetic and Photophysical Investigations. Inorg. Chem. 2012; 51: 8488-8501.

[62] Wu J, Dupont N, Liu S-X, Neels A, Hauser A, Decurtins S. Imidazole-Annulated Tetrathiafulvalenes Exhibiting pH-Tuneable Intramolecular Charge Transfer and redox Properties. Chem. Asian J. 2009; 4: 392-399.

[63] Feng M, Pointillart F, Le Guennic B, Lefeuvre B, Golhen S, Cador O, Maury O, Ouahab L. Unprecedented Sensitization of Visible and Near-Infrared Lanthanide Luminescence by Using a Tetrathiafulvalene-Based Chromophore. Chem. Asian J. 2014; 9: 2814-2825. 
[64] Lannes A, Intissar M, Suffren Y, Reber C, Luneau D. Terbium(III) and yttrium(III) complexes with pyridine-substituted nitronyl nitroxide radical and different betadiketonate ligands. Crystal structures and magnetic and luminescence properties. Inorg. Chem. 2014; 53: 9548-9560. 